\title{
Elder American Indian Women's Knowledge of Pelvic Floor Disorders and Barriers to Seeking Care
}

\author{
Gena C Dunivan, M.D, \\ Division of Urogynecology Department of OBGYN University of New Mexico Albuquerque, NM \\ Yuko M Komesu, M.D, \\ Division of Urogynecology Department of OBGYN University of New Mexico Albuquerque, NM \\ Sara B Cichowski, M.D, \\ Division of Urogynecology Department of OBGYN University of New Mexico Albuquerque, NM \\ Christine Lowery, Ph.D., MSW [Community Member], \\ Former president of New Mexico Indian Council on Aging \\ Jennifer T Anger, M.D., M.P.H, and \\ Department of Urology Cedars-Sinai Medical Center Beverly Hill, CA \\ Rebecca G Rogers, M.D \\ Division of Urogynecology Department of OBGYN University of New Mexico Albuquerque, NM
}

\section{Abstract}

Objectives-To evaluate urinary incontinence and pelvic organ prolapse knowledge among elder Southwestern American Indian women and to assess barriers to care for pelvic floor disorders through Community Engaged Research.

\begin{abstract}
Methods-Our group was invited to provide an educational talk on urinary incontinence and pelvic organ prolapse at an annual meeting of American Indian Elders. Female attendees $\geq 55$ years anonymously completed demographic information and two validated questionnaires; the Prolapse and Incontinence Knowledge Questionnaire (PIKQ) and Barriers to Incontinence Care Seeking Questionnaire (BICS-Q). Questionnaire results were compared to historical controls from the original PIKQ and BICS-Q validation study.
\end{abstract}

Results-144 women completed questionnaires. The mean age was $77.7 \pm 9.1$ years. The mean PIKQ UI score was $6.6 \pm 3.0$ (similar to historic gynecology controls $6.8 \pm 3.3, \mathrm{p}=0.49$ ) and the mean PIKQ POP score was $5.4 \pm 2.9$ (better than historic gynecology controls $3.6 \pm 3.2, \mathrm{p}<0.01$ ). Barriers to care seeking reported by the elder women were highest on the BICS-Q subscales of "Cost" and "Inconvenience".

CORRESPONDING AUTHOR: Gena Dunivan, M.D. 1 University of New Mexico MSC 10-5580 Albuquerque, NM 87131-0001 505-925-4395 (work) 505-272-1336 (fax) gdunivan@ salud.unm.edu.

PRESENTATION INFORMATION: Oral presentation at the American Urogynecologic Society $34^{\text {nd }}$ Annual Scientific Meeting in Las Vegas, NV. October 16-19th, 2013.

DISCLOSURE: Rebecca G Rogers, MD is DSMB chair for the TRANSFORM trial sponsored by American Medical Systems 
Conclusions-Urinary incontinence knowledge is similar to historic gynecology controls and pelvic organ prolapse knowledge is higher than historic gynecology controls among elder Southwestern American Indian women. American Indian elder women report high levels of barriers to care. The greatest barriers to care seeking for this population were related to cost and inconvenience, reflecting the importance of assessing socioeconomic status when investigating barriers to care. Addressing these barriers may enhance care seeking Southwestern American Indian women.

\section{Keywords}

American Indian; Barriers to care; Barriers to Incontinence Care Seeking Questionnaire; Pelvic Floor Disorders; Prolapse and Incontinence Knowledge Questionnaire

\section{Introduction}

Pelvic floor disorders (PFD) are common with a prevalence of $15.7 \%$ for urinary incontinence and $2.9 \%$ for pelvic organ prolapse [1]. Despite the prevalence of these disorders, multiple studies have shown that the majority of patients with urinary incontinence do not seek care from a healthcare provider [2-4]. In fact, only $25 \%$ of women surveyed from a primary care clinic knew the meaning of the three terms of urinary incontinence, pelvic organ prolapse, and pelvic floor disorder [5]. Providing education to increase knowledge and education about pelvic floor disorders may improve health seeking behavior for women with pelvic floor problems [6,7]. Using a validated questionnaire, Shat et al. reported that overall urinary incontinence knowledge is better than pelvic organ prolapse knowledge. White race and higher education were associated with better knowledge of urinary incontinence. However, race, education, and income did not have a significant effect on knowledge regarding pelvic organ prolapse [8].

Multiple barriers to care seeking for urinary incontinence have been identified including embarrassment and shame, the misperception that urinary incontinence is a normal part of aging, the view that urinary incontinence was less important compared to other medical problems and lack of knowledge of effective treatment options [9-13]. Factors that are associated with increased care seeking include increased age, prior surgery for urinary incontinence, increased severity of urinary incontinence, and having a regular doctor and routine pelvic exams [4].

While knowledge of barriers to care has improved and there has been an increased focus on the inclusion of minorities in the urogynecologic literature, very little is known about American Indians and pelvic floor disorders. This information gap includes lack of knowledge regarding its prevalence, barriers to care, health seeking behaviors and patient understanding of pelvic floor disorders. Prior work is limited to one study which describes the prevalence of urinary incontinence among women who were members of a South Dakota tribe [14] and another describing the level of bother American Indian women experience regarding pelvic organ prolapse compared to Hispanic and non-Hispanic white women [15].

The Centers for Disease Control and Prevention defines community engagement as, "the process of working collaboratively with and through groups of people affiliated by 
geographic proximity, special interest or similar situations to address issues affecting the well-being of those people" [16]. Community based research is becoming increasingly recognized as important for collaborative work between the community and academia, especially with communities that may have had negative experiences with researchers in the past [17]. This project encompasses a community based approach.

Our objectives were to evaluate knowledge about urinary incontinence and pelvic organ prolapse among elder Southwestern American Indian women and assess knowledge by comparing questionnaire scores of these American Indian women to historic controls. We also sought to assess barriers to seeking care for pelvic floor disorders among elder Southwestern American Indian women.

\section{Materials and Methods}

\section{Community Approach}

The University of New Mexico (UNM) Urogynecology group was invited to provide an educational talk on urinary incontinence and pelvic organ prolapse at a regular meeting of Southwestern American Indian Elders. Health education, including health policy, was the focus for a two-year cycle (six sessions) for this long-standing, elder association. Attendees were primarily from the Pueblos in New Mexico and were mostly women. The purpose of the organization is to educate elders from member senior centers in the state. This study received IRB/HRRC exemption status (HRRC\# 12-130).

\section{Questionnaire Administration}

Prior to the educational session, female American Indian attendees $\geq 55$ years were invited to complete demographic information and validated questionnaires anonymously. This included the Prolapse and Incontinence Knowledge Questionnaire (PIKQ) [7] and Barriers to Incontinence Care Seeking Questionnaire (BICS-Q) [18]. The PIKQ is comprised of two 12-item questionnaires assessing knowledge of urinary incontinence (PIKQ UI) and pelvic organ prolapse (PIKQ POP). Respondents answer, "agree", "disagree" or "don't know" to a series of statements on urinary incontinence or pelvic organ prolapse. Correct answers are given a score of one, incorrect or don't know answers are scored with zero, for a total score range of 0 to 12 points possible for each scale. Higher scores indicate greater knowledge of urinary incontinence and/or pelvic organ prolapse. Questionnaire results were compared to historical controls from the original PIKQ validation study, which studied a younger population of women presenting to either gynecology or urogynecology clinics. In the original validation study the urogynecology participants were recruited from a population of patients seen in urogynecologic follow-up. They were expected to have higher scores as they were assumed to have received some education regarding pelvic floor disorders. The mean age of the gynecology groups was 35.5 years $\pm 10.7,55.0 \%$ had a college education, and $45.7 \%$ were white. In the urogynecology group, the mean age was $55.7 \pm 17.4,43.6 \%$ had completed college, and $89.7 \%$ were white [7].

The BICS-Q is a 14-item questionnaire which measures patient-reported barriers to care seeking for urinary incontinence. Subjects answer, "not at all", "slightly", "moderately", or 
"greatly" to describe the degree of barriers to care. These responses are scored from 0 to 3 , with a total score ranging from 0 to 36 with higher scores indicate decreased likelihood of seeking care. The BICS-Q has several subscales, which include Inconvenience,

Relationship, Site Related, Cost, and Fear. Results were again compared to historic controls from the original BICS-Q study [18]. The BICS-Q allows only for the ranking of the barrier, it does not have any space for additional space or clarification of questions.

\section{Patient Outreach}

The UNM Urogynecology team, which included two urogynecologists, one Urogynecology fellow, one pelvic floor physical therapist, one certified nurse midwife expert in pessary care, and two Urogynecology nurses, attended the elder's meeting which was located approximately 30 minutes outside of Albuquerque, New Mexico. All elder, American Indian women were invited to complete the questionnaires. We chose to exclude women of less than 55 years of age to avoid including data from the elder women's caregivers or family that may have accompanied them to the meeting. After completing questionnaires, meeting attendees received lectures on urinary incontinence, pelvic organ prolapse and an in depth discussion of treatment options. Treatment options discussed included both surgical and non-surgical treatments such as pessary and physical therapy and women had the opportunity to participate in physical therapy exercises.

\section{Statistics Analysis}

Data were analyzed using SAS v9.3 (Cary, NC). Descriptive statistics and Pearson correlations were performed to assess relationships between questionnaire scores and participant characteristics. One sided t-tests were used to compare American Indian Elder scores to historic controls.

\section{Results}

It was estimated that approximately 200 elders attended the meeting and approximately $10 \%$ were male. A total of 157 women completed the questionnaire. Nine were excluded as they reported their age as younger than 55 years and four were excluded, as they did not identify their race as American Indian. The mean age was 77.7 years \pm 9.1 with a range of 55 to 90 years. The median parity was 3.5 (LQ 2, UQ 5) and ranged from 0 to 11 . The majority of respondents $(62 \%, 91 / 146)$ had a high school education or less, $47 \%(53 / 113)$ reported an annual income of less than $\$ 10,000$, and only $10.3 \%(15 / 145)$ had worked in the medical field. Sixty three percent (N=93) of women reported personal urinary leakage, and 20\% $(\mathrm{N}=39)$ reported having pelvic organ prolapse based on self-reported symptoms. The mean score for the PIKQ UI was $6.6 \pm 3.0$ and the mean score for the PIKQ POP was $5.4 \pm 2.9$. Examples of questions and percentages of correct or incorrect answers for the PIKQ - UI and PIKQ- POP are shown in Table 1. Compared to historic gynecology controls, elder American Indian women had similar knowledge regarding urinary incontinence, see Table 2. They also had higher knowledge regarding pelvic organ prolapse when compared to the gynecology controls. In the original validation paper [7], it was expected that the Urogynecology group would have higher scores as they were all seen in follow-up and were expected to have received educational counseling at prior visits. This finding was confirmed 
in our study. As expected, when compared to the Urogynecology controls, American Indian elders were found to have lower knowledge of both urinary incontinence and pelvic organ prolapse. (Table 2)

Barriers to care seeking reported by elder American Indian women via the BICSQ was significantly higher than that of historic controls $(12.3 \pm 9.6$, vs. $4.72 \pm 6.28, \mathrm{p}<0.001)$, indicating more barriers to care. The original validation paper did not include the mean scores for the subscales and are therefore not included. In the present study, the highest scoring subscales of the BICS-Q were Cost and Inconvenience. (Table 3) The most frequently cited barriers were long delays before copay reimbursement with $29.7 \%$ reporting that this "greatly" prevented them from seeking care, and prolonged wait times for appointments, with $19.7 \%$ reporting this "greatly" prevented them from seeking care.

Correlations were also examined to determine if patient characteristics were associated with PIKQ or BICS-Q scores. For the PIKQ UI there was a weak correlation between increasing age and decreasing score, $R h o=-0.20, p=0.027$, i.e. as age increased urinary incontinence and prolapse knowledge decreased. There was also a weak correlation with the BICS-Q and income, $R h o=-0.25, \mathrm{p}=0.038$, i.e. as the respondents' income increased the barrier to care seeking decreased. There were no significant correlations found with the PIKQ POP.

\section{Discussion}

Knowledge regarding urinary incontinence and pelvic organ prolapse among elder Southwestern American Indian women is similar to historic gynecology controls but lower than an urogynecologic controls. American Indian elder women reported greater barriers to care than the historical control group, despite the majority of American Indian elder women in this community having medical care coverage through Indian Health Service (IHS).

However, this is complicated by underfunding of the IHS which according to 2011 data was only at about $50 \%$ of what was requested [19]. Also, contract health services (CHS) are frequently needed for subspecialty care and cases are prioritized based on "medical priorities of care" [20]. Therefore, IHS contract health care dollars are limited and care seeking may require significant individual investment, including time, transportation, and copays. The greatest barriers to care seeking for this population were related to cost and the inconvenience of prolonged wait times for appointments. This finding highlights the overall importance of poverty when assessing barriers to care as almost half of our population reported an annual income of less than $\$ 10,000$. It has been established that low socioeconomic status is associated with poorer health and a variety of medical conditions, including increased cardiovascular risk, type II diabetes, and cancer [21-24]. This study demonstrates that care seeking for pelvic floor disorders is also adversely affected by low socioeconomic status.

According to the US census data, American Indian or Alaska Natives comprise $1.2 \%$ of the population of the United States [25]. The state of New Mexico has a unique demographic make-up with the one of the larger population of American Indians in the United States comprised of 22 American Indian Tribes [26]. According to the United States Census 
Bureau in 2012, 10.2\% of the population in New Mexico reported themselves as American Indian or Alaskan Native [27].

The literature on American Indian women in the urogynecologic field is quite limited. One study specifically addressed urinary incontinence prevalence among women in a South Dakota tribe[14]. The authors reported a lower overall prevalence of urinary incontinence seen in this cross-sectional sampling of one American Indian tribe based on the Urogenital Distress Inventory. This study and ours take the first steps in assessing knowledge and identifying barriers that American Indian women face with pelvic floor disorders.

We began this research at the invitation of a community requesting more education on pelvic floor disorders for their elder population. Community engaged research has gained increasing popularity, especially when working with underserved or minority populations. This is especially pertinent as goals for community engagement include not only improved communication and trust building but also addressing health disparities and improving health outcomes [16]. Based on this first step, we now have preliminary data to move forward with the development of educational interventions. We will then evaluate the effect of these interventions on improving health understanding, reducing barriers to seeking care, and eventually improving outcomes.

Strengths of this study include the community based approach and the use of validated questionnaires for both knowledge and barriers to seeking care. Also, this is one of the few studies specifically addressing knowledge and barriers to care in an American Indian population related to pelvic floor disorders. Limitations include the small sample size and importantly, although the participants were from many New Mexican tribes, the results may not be generalizable to other American Indian communities. Also the PIKQ questionnaire used may not be culturally appropriate for all communities. It also does not capture the experience and knowledge that women may have gained from their community and groups. It may also not accurately reflect how American Indian women traditionally express their knowledge. Also, although almost 50\% of the population reported their income of $<\$ 10,000$ this is a mainly retired population and this number may not accurately reflect other support as many women in this community have pueblo communal living resources that are not documented. Finally, comparisons using historic controls are problematic; understanding that the historic controls had many inherent differences than this study's population, such as age, limits the interpretability of the results. However, given that there are not yet normative data established for these questionnaires, we felt it was valuable to present historical comparison data for reference.

Future directions for this work include further development of our community partnership and further exploration of the prevalence of pelvic floor disorders among this population of American Indian women. From this we plan to develop culturally sensitive educational interventions. Paramount next steps include investigating ways to reduce barriers with the ultimate goal of improving health seeking behavior and treatment outcomes. 


\section{Acknowledgments}

FINANCIAL SUPPORT: This project was supported in part by the National Center for Research Resources and the National Center for Advancing Translational Sciences of the National Institutes of Health through Grant Number UL1 TR000041. The content is solely the responsibility of the authors and does not necessarily represent the official views of the NIH.

\section{REFERENCES}

1. Nygaard I, Barber MD, Burgio KL, et al. Pelvic Floor Disorders Network. Prevalence of symptomatic pelvic floor disorders in US women. JAMA. 2008; 300(11):1311-1316. [PubMed: 18799443]

2. Harris SS, Link CL, Tennstedt SL, et al. Care seeking and treatment for urinary incontinence in a diverse population. J Urol. 2007; 177(2):680-4. [PubMed: 17222656]

3. Svihra J, Luptak J, Svihrova V, et al. Gender-specific external barriers to seeking care for urinary incontinence. Patient Preference and Adherence. 2012; 6:773-779. [PubMed: 23152671]

4. Berger MB, Patel DA, Miller JM, et al. Racial differences in self-reported healthcare seeking and treatment for urinary incontinence in community-dwelling women from the EPI study. Neurourol Urodyn. 2011; 30(8):1442-1447. [PubMed: 21717504]

5. Senekjian L, Heintz K, Egger MJ, et al. Do women understand urogynecologic terminology? Female Pelvic Med Reconstr Surg. 2011; 17(5):215-217. [PubMed: 21984964]

6. Kubik K, Blackwell L, Heit M. Does socioeconomic status explain racial differences in urinary incontinence knowledge? Am J Obstet Gynecol. 2004; 191(1):188-93. [PubMed: 15295363]

7. Shah AD, Massagli MP, Kohli N, et al. A reliable, valid instrument to assess patient knowledge about UI and pelvic organ prolapse. Int Urogynecol J Pelvic Floor Dysfunct. Sep. 2008; 19(9): 1283-9. [PubMed: 18480958]

8. Shah AD, Shott S, Kohli N, et al. Do racial differences in knowledge about urogynecologic issues exist? Int Urogynecol J. 2008; 19:1371-1378.

9. El-Azab AS, Shaaban OM. Measuring the barriers against seeking consultation for urinary incontinence among Middle Eastern women. BMC Womens Health. 2010; 10(3):1-9. [PubMed: 20064263]

10. Shaw C, Tansey R, Jackson C, et al. Barriers to help seeking in people with urinary symptoms. Fam Pract. 2001; 18(1):48-52. [PubMed: 11145628]

11. Margalith I, Gillon G, Gordon D. Urinary incontinence in women under 65: quality of life, stress related to incontinence and patterns of seeking health care. Qual Life Res. 2004; 13(8):1381-90. [PubMed: 15503833]

12. Teunissen D, van Weel C, Lagro-Janssen T. Urinary incontinence in older people living in the community: examining help-seeking behaviour. Br J Gen Pract. 2005; 55(519):776-82. [PubMed: 16212853]

13. Basu M, Duckett JR. Barriers to seeking treatment for women with persistent or recurrent symptoms in urogynaecology. BJOG. 2009; 116(5):726-30. [PubMed: 19220235]

14. Fiegen MM, Benson KD, Hanson JD, et al. The prevalence of urinary incontinence in American Indian women from a South Dakota tribe. Int Urogynecol J. 2012; 23(4):473-9. [PubMed: 22159561]

15. Dunivan GC, Cichowski SB, Komesu YM, et al. Ethnicity and variations of pelvic organ prolapse bother. Int Urogynecol J. Jun 27.2013 [Epub ahead of print].

16. [July 23, 2013] Principles of Community Engagement.. Clinical and Translational Science Awards Consortium, Community Engagement Key Function Committee Task, Force on the Principles of Community Engagement. 2nd Edition.NIH Publication No. 11-7782. Available at: http:// www.atsdr.cdc.gov/communityengagement/pdf/PCE_Report_508_FINAL.pdf.

17. Holkup PA, Rodehorst TK, Wilhelm SL, et al. Negotiating three worlds: academia, nursing science, and tribal communities. J Transcult Nurse. 2009; 20:164-175.

18. Heit M, Blackwell L, Kelly S. Measuring barriers to incontinence care seeking. Neurourol Urodyn. 2008; 27(3):174-8. [PubMed: 17621356] 
19. Health care for urban American Indian and Alaska Native women. Committee Opinion No. 515. American College of Obstetricians and gynecologists. Obstet Gynecol. 2012; 119:201-5. [PubMed: 22183240]

20. Indian Health Service. [August 30, 2013] Newsroom Fact Sheets.. Contract Health Services. Available at: http://www.ihs.gov/newsroom/factsheets/contracthealthservices/.

21. Adler N, Stewart J. Health disparities across the lifespan: meaning, methods, and mechanisms. Ann NY Acad Sci. 2010; 1186:5-23. [PubMed: 20201865]

22. Naess O, Strand BH, Smith GD. Childhood and adulthood socioeconomic position across 20 causes of death: a prospective cohort study of 800,000 Norwegian men and women. J Epidemiol Community Health. 2007; 61(11):1004-9. [PubMed: 17933960]

23. Pollitt RA, Rose KM, Kaufman JS. Evaluating the evidence for models of life course socioeconomic factors and cardiovascular outcomes: a systemic review. BMC Public Health. 2005; 20(5):7. [PubMed: 15661071]

24. Raphael D. Poverty in childhood and adverse health outcomes in adulthood. Maturitas. 2011; 69(1):22-6. [PubMed: 21398059]

25. [August 2nd, 2013] State \& County QuickFacts [United States Census Bureau Website]. Available at: http://quickfacts.census.gov/qfd/states/00000.html.

26. [July 23, 2013] Native American [New Mexico True Website]. Available at: http:// www.newmexico.org/native-american.

27. [July 23, 2013] State \& County QuickFacts [United States Census Bureau Website]. Available at: http://quickfacts.census.gov/qfd/states/35000.html. 


\section{Table 1}

\section{Examples of PIKQ-UI and PIKQ-POP Questions}

\begin{tabular}{|l|c|c|c|}
\hline PIKQ-UI Questions & $\begin{array}{c}\text { Answered } \\
\text { Correctly N (\%) }\end{array}$ & $\begin{array}{c}\text { Answered } \\
\text { Incorrectly N (\%) }\end{array}$ & $\begin{array}{c}\text { Answered "Don't } \\
\text { Know" N (\%) }\end{array}$ \\
\hline $\begin{array}{l}\text { "Other than pads and diapers, not much can be done to treat leakage of } \\
\text { urine." }\end{array}$ & $78(52.4 \%)$ & $32(21.5 \%)$ & $39(26.2 \%)$ \\
\hline "Surgery is the only treatment for urinary leakage." & $78(51.7 \%)$ & $20(13.3 \%)$ & $53(35.1 \%)$ \\
\hline PIKQ_POP Questions & & & \\
\hline $\begin{array}{l}\text { "A rubber ring called a pessary can be used to treat symptoms of pelvic } \\
\text { organ prolapse." }\end{array}$ & $50(34.7 \%)$ & $9(6.3 \%)$ & $85(59.0 \%)$ \\
\hline "People who are obese are less likely to get pelvic organ prolapse." & $48(34.0 \%)$ & $30(21.3 \%)$ & $63(44.7 \%)$ \\
\hline
\end{tabular}


Table 2

Comparison to Historic Controls

\begin{tabular}{|l|c|c|c|}
\hline & Present Study & \multicolumn{2}{|c|}{ Historic Controls } \\
\hline & $\begin{array}{c}\text { Native American Population } \\
\text { Mean Score } \pm \text { SD N=157 }\end{array}$ & $\begin{array}{c}\text { Gynecology Population Mean Score } \pm \\
\text { SD }^{*} \text { N=133 }\end{array}$ & $\begin{array}{c}\text { Urogynecology Population Mean Score } \pm \\
\text { SD }^{*} \text { N=61 }\end{array}$ \\
\hline PIKQ UI & $6.6 \pm 3.0$ & $6.8 \pm 3.3$ & $8.8 \pm 2.4$ \\
& & $\mathrm{p}=0.49$ & $<0.001$ \\
\hline PIKQ & $5.4 \pm 2.9$ & $3.6 \pm 3.2$ & $8.2 \pm 3.4$ \\
POP & & $\mathrm{p}<0.001$ & $\mathrm{p}<0.001$ \\
\hline
\end{tabular}

* All comparisons are between Native American Elder women and historic controls. 


\section{Table 3}

BISC-Q and Subscales with Example Statement

\begin{tabular}{|l|c|c|}
\hline & Mean Score \pm SD & $\begin{array}{c}\text { Range (Minimum - } \\
\text { Maximum) }\end{array}$ \\
\hline BISC-Q Total Score & $12.3 \pm 9.6$ & $0-36$ \\
\hline $\begin{array}{l}\text { BISC-Q Subscales } \\
\text { "Thenvenience } \\
\text { "The wait is too long at the time of the appointment." }\end{array}$ & $3.23 \pm 3.0$ & $0-9$ \\
\hline $\begin{array}{l}\text { Relationship } \\
\text { "The health care practitioner and his staff aren't interested in my worries about my health" }\end{array}$ & $2.32 \pm 2.3$ & $0-9$ \\
\hline $\begin{array}{l}\text { Site-related } \\
\text { "There is no transportation to the office or clinic." }\end{array}$ & $1.31 \pm 1.7$ & $0-6$ \\
\hline $\begin{array}{l}\text { Cost } \\
\text { "There are long delays before insurance repays out-of-pocket expenses." }\end{array}$ & $3.57 \pm 3.2$ & $0-9$ \\
\hline $\begin{array}{l}\text { Fear } \\
\text { "I don't like to be examined or asked a lot of questions." }\end{array}$ & $2.48 \pm 2.5$ & $0-9$ \\
\hline
\end{tabular}

